\title{
SUSTAINABILITY DEVELOPMENT GOALS PREFERENCES IN METALLURGICAL AND MINING INDUSTRY
}

\author{
${ }^{1}$ Radim LENORT, ${ }^{2}$ František ZAPLETAL, ${ }^{1}$ Pavel WICHER, ${ }^{3}$ Nadezhda SHMELEVA \\ ${ }^{1}$ VSB - Technical University of Ostrava, Faculty of Materials Science and Technology, Ostrava, Czech \\ Republic,EU, radim.lenort@vsb.cz, pavel.wicher@vsb.cz \\ ${ }^{2}$ VSB - Technical University of Ostrava, Faculty of Economics, Ostrava, Czech Republic, EU, \\ frantisek.zapletal@vsb.cz \\ ${ }^{3}$ National University of Science and Technology “MISIS”, Moscow, Russia, nshmeleva@misis.ru
}

https://doi.org/10.37904/metal.2020.3643

\begin{abstract}
Sustainable development goals (SDGs) adopted by all United Nations Member States in 2015 provide an opportunity for the metallurgical and mining industry to create value for both their business and society. The aim of the paper is to analyze the SDGs preferences in the metallurgical and mining industry and identify those SDGs that companies from that industry promised to follow. The multi-criteria decision-making method PROMETHEE and the GAIA plane were used as the methodological base for analysis of input data from United Nations Global Compact database. The results show main differences in declared SDGs preferences among Europe, America, Asia, and Africa.
\end{abstract}

Keywords: Sustainable development goals, metallurgical and mining industry, PROMETHEE method, GAIA plane

\section{INTRODUCTION}

Customers, investors, governmental and non-governmental organizations, employees, and other stakeholders are increasing their demands for the continuous development of corporate sustainability, thereby increasing the pressure to implement sustainable corporate strategy. As a result, this concept is becoming key for many companies. In the metallurgical and mining industries, this trend is further supported by their high environmental and social impacts. One of the basic tools of corporate sustainability is regular and systematic reporting. Currently, companies are beginning to report their sustainability performance in accordance with The 2030 Agenda for Sustainable Development by the United Nations. The Sustainable Development Goals (SDGs) adopted by all United Nations Member States in 2015 are one of the key elements of this plan. The subject of the paper is the analysis of the SDGs preferences in the metallurgical and mining industry. The aim of the paper is to analyze the SDGs preferences in the metallurgical and mining industry and identify those SDGs that companies from that industry promised to follow. The paper studies how these preferences differ across Europe, America, Asia, and Africa. PROMETHEE method and the GAIA plane were used as the methodological base for meeting the aim.

\section{LITERATURE REVIEW}

Corporate Sustainability refers to a company's activities - voluntary by definition - demonstrating the inclusion of social and environmental concerns in business operations and in interactions with stakeholders [1]. Lo and Sheu [2] found that companies are rewarded in the market for taking economic as well as environmental and social concerns into their developing strategies. It confirms the finding that the corporate sustainability concept is also base of modern value-increasing strategies of industrial corporations. 
The sustainability concept alone is rather old and was for the first time comprehensively presented in 'Our Common Future' report by the World Commission on Environment and Development (Brundtland Commission) in 1987 [3]. This report introduced three dimensions of sustainability: economic growth, environmental protection, and social equality. This concept was further developed into the Triple Bottom Line (TBL) concept [4], which attempts to treat all the three dimensions of sustainability with equal importance and thus could be considered an integrative theory of sustainability [5].

The implementation of a corporate sustainable strategy goes hand in hand with the reporting. The percentage of the companies in the S\&P 500 Index publishing their sustainability report increased from $20 \%$ in 2011 to $86 \%$ in 2018 [6]. One of the current trends is to report in accordance with The 2030 Agenda for Sustainable Development which contains 17 SDGs.

The 17 SDGs are the world's plan to build a sustainable planet by 2030. Adopted by all United Nations Member States in 2015, the SDGs are a call for action by all countries to promote prosperity while protecting the environment [7]: (1) No poverty, (2) Zero hunger, (3) Good health and well-being, (4) Quality education, (5) Gender equality, (6) Clean water and sanitation, (7) Affordable and clean energy, (8) Decent work and economic growth, (9) Industry, innovation and infrastructure, (10) Reduced inequalities, (11) Sustainable cities and communities, (12) Responsible consumption and production, (13) Climate action, (14) Life below water, (15) Life on land, (16) Peace, justice and strong institutions, (17) Partnerships for the goals.

\section{METHODOLOGICAL BASE}

The family of PROMETHEE methods belongs to the outranking multi-criteria decision-making (MCDM) methods, which are based on special outranking relations. The original PROMETHEE algorithm introduced by [8] aims to solve the ranking problems (to get the ranking of alternatives). Then, this original algorithm has been extended to address also other types of MCDM problems, including the clustering [9] and visualization of alternatives' profiles via the GAIA plane [10].

The main motivation, why to use the PROMETHEE methods in general, is their excellent traceability, computational simplicity, and available graphical outputs with visualized results. Further, we describe only the part of methodology, which is necessary for analysis of the alternatives' profile and their visualization in the GAIA plane.

Let us assume the problem with $k$ criteria and $m$ alternatives. The aim of the analysis is to explore the patterns in performances of the alternatives in terms of the criteria (whether similarities or differences). The algorithm can be split into the following 3 steps:

- $\quad$ All the ordered $m \cdot(m-1)$ pairs are pairwisely compared in terms of each criterion. This is done using the preference function $p_{i}(x)$ (non-decreasing function with the range $[0 ; 1]$ and $p(x)=0$ for $x \leq 0$ ), which assigns the so called preference degree $P_{i}\left(x_{i}^{j}, x_{i}^{r}\right)$ to the difference in performances of the alternatives $j$ and $r$ (for all the pairs of alternatives) in terms of the $i$-th criterion ([8] introduced 6 standardized types of the preference functions).

- $\quad$ The preference degrees $P_{i}\left(x_{i}^{j}, x_{i}^{r}\right)$ are aggregated into the so called unicriterion flow for the $i$-th criterion using (1). Thus, at the end of this step, each alternative is described by the $k$-dimensional vector of the unicriterion flows $\phi(j)=\left(\phi_{1}(j), \ldots, \phi_{k}(j)\right)$.

$$
\phi_{i}(j)=\frac{1}{m-1} \sum_{j \neq r}\left(P_{i}\left(x_{i}^{j}, x_{i}^{r}\right)-P_{i}\left(x_{i}^{r}, x_{i}^{j}\right)\right), \quad i=1, \ldots, k, \quad j=1, \ldots, m,
$$

- To obtain the visualizable representation of the alternatives and criteria in the so called GAIA plane, the Principle Component Analysis (PCA) must be applied to the vectors of unicriterion flows from the 
previous step. This method reduces the number of dimensions and provides the projection of the system onto the plane. According to [10], the quality of the projection in the GAIA plane is good enough, if the plane displays at least $80 \%$. In the GAIA plane, each criterion is represented as the vector going from the origin of the coordinate system and each alternative is given as the point. The mutual position of the alternatives and criteria provides important information about the modelled problem - patterns of alternatives' performances and dependencies between criteria can be revealed in this way. The following rules for the interpretation of the GAIA plane hold: (1) alternatives lying in a similar direction from the origin have a similar performance profile (and vice versa), (2) when an alternative lies in a similar direction as a criterion, this alternative performs well in the given criterion (and other way around, an alternative performs poorly in terms of a criterion lying in an opposite direction from the origin), (3) the longer a vector of criterion is, the greater distinguishing power this criterion has for the problem. The so called GAIA action profiles can be derived from the GAIA plan. The action profile stems from the GAIA plane, but displays also the values of unicriterion net flows of the alternative $\left(\pi_{j}\left(A_{i}\right)\right)$. The action profile uses the bar chart where values above the axis mean that this flow is positive, and thus the alternative performs better in general than the others in terms of this criterion, and vice versa.

\section{INPUT DATA}

The input data for the study were taken from the United Nations (UN) Global Compact database [11]. The database provides sustainability information about almost 14,500 participants from 155 countries around the world. The participants are divided into 20 sectors and 42 sub-sectors. The study is based on the Basic Resources sector and Industrial Metals \& Mining sub-sector, which contains 118 active participants. Each participant should submit to the database the Communication on Progress (COP), which includes answer to the following question: "Which of the following Sustainable Development Goals (SDGs) do the activities described in your COP address?". In this way, companies declare which SDGs they follow. In the studied sector, 90 companies provided answers to this question. The binary values were obtained on this basis.

The division of companies in terms of continents is as follows: Europe -45 companies $(50.00 \%)$, Asia -22 companies (24.44\%), America - 19 companies (21.11\%), Africa - 3 companies (3.33\%), and Australia - 1 company $(1.11 \%)$. This shows that the number of companies from Africa is not statistically significant enough, which must be considered when interpreting the results. As Australia is represented by only one company, it was excluded from the analysis.

To get the performance values for the continents, the arithmetic mean of binary values was used, i.e. the relative frequency with which the companies in the particular continent follows the given SDG (e.g., the value of 0.5 means that half of companies in the continent follows the SDG and the second half not). The resulting input data are provided in Table 1.

Table 1 Input data for PROMETHEE method and GAIA plane

\begin{tabular}{|c|c|c|c|c|c|c|c|c|c|c|c|c|c|c|c|c|c|}
\hline Continent / SDG & $\mathbf{1}$ & $\mathbf{2}$ & $\mathbf{3}$ & $\mathbf{4}$ & $\mathbf{5}$ & $\mathbf{6}$ & $\mathbf{7}$ & $\mathbf{8}$ & $\mathbf{9}$ & $\mathbf{1 0}$ & $\mathbf{1 1}$ & $\mathbf{1 2}$ & $\mathbf{1 3}$ & $\mathbf{1 4}$ & $\mathbf{1 5}$ & $\mathbf{1 6}$ & $\mathbf{1 7}$ \\
\hline Africa & 1.00 & 0.33 & 0.67 & 1.00 & 1.00 & 0.33 & 0.33 & 1.00 & 0.33 & 0.33 & 0.33 & 0.33 & 0.33 & 0.00 & 0.67 & 0.67 & 0.00 \\
\hline America & 0.47 & 0.26 & 0.68 & 0.79 & 0.53 & 0.89 & 0.47 & 0.95 & 0.63 & 0.47 & 0.58 & 0.47 & 0.68 & 0.26 & 0.74 & 0.63 & 0.47 \\
\hline Asia & 0.64 & 0.55 & 0.86 & 0.82 & 0.82 & 0.82 & 0.86 & 0.77 & 0.77 & 0.55 & 0.68 & 0.91 & 0.82 & 0.36 & 0.64 & 0.68 & 0.64 \\
\hline Europe & 0.18 & 0.07 & 0.56 & 0.44 & 0.40 & 0.42 & 0.44 & 0.69 & 0.62 & 0.27 & 0.31 & 0.69 & 0.56 & 0.16 & 0.38 & 0.40 & 0.51 \\
\hline
\end{tabular}

\section{RESULTS}

The results were obtained using Visual PROMETHEE software. As for the types of preference functions suitable for this analysis, the situation is rather complicated because no justified reason, how to decide what 
values of differences in performances should be considered negligible (or absolutely important), exists. Therefore, we decided to follow [12] and use the Gaussian preference function described as

$$
p_{i}(x)=1-\exp \left(-x^{2} / 2 \sigma^{2}\right), i=1, \ldots, k,
$$

with the parameter $\sigma$ equal to the standard deviation of all alternatives' performances in terms of the $i$-th criterion.

Analysis of the frequency of occurrence of individual SDGs shows that metallurgical and mining industry worldwide prefer to follow next SDGs: 8 Decent work and economic growth, 12 Responsible consumption and production, 3 Good health and well-being, 9 Industry, innovation and infrastructure, and 13 Climate action. On the contrary, the following SDGs are followed the least often: 14 Life below water, 2 Zero hunger, 1 No poverty, 10 Reduced inequalities, and 11 Sustainable cities and communities.

Figure 1 shows the GAIA plane for studied input data. Quality of the GAIA projection is $88.5 \%$, which guarantees reliable results. Africa, Asia and Europe (alternatives) are situated in different quadrants, America is located near to the center of the plane. This means that the companies from individual continents tend to follow very different SDGs (criteria), which are represented by the blue vectors in the plane (only Asia and America have at least some similarities in patterns of behavior).

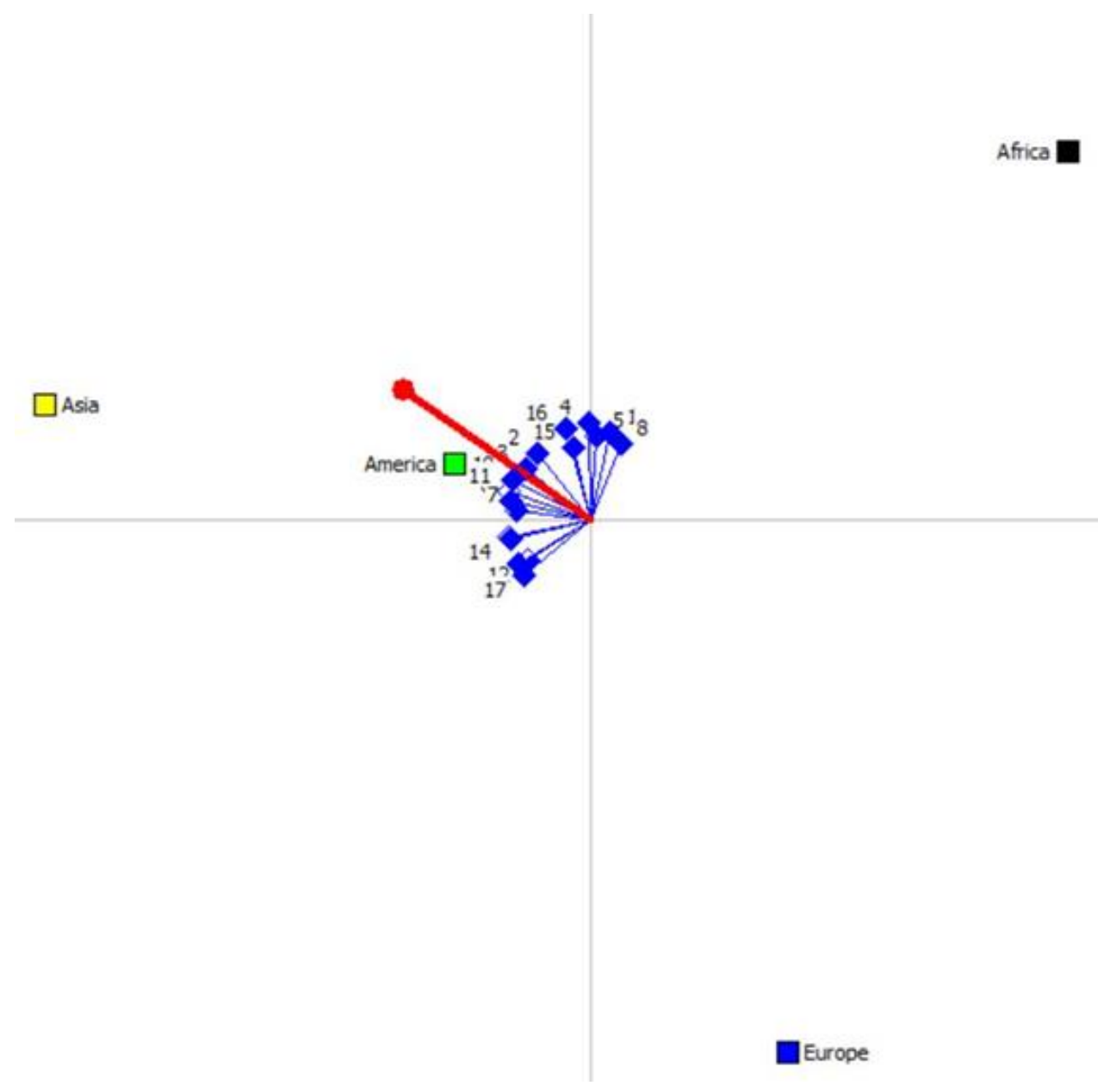

Figure 1 GAIA plane

Figure 2 shows the GAIA action profiles. These profiles are based on the unicriterion flows $\phi_{i}(j)(1)$ and allow to compare one continent with all other ones. 


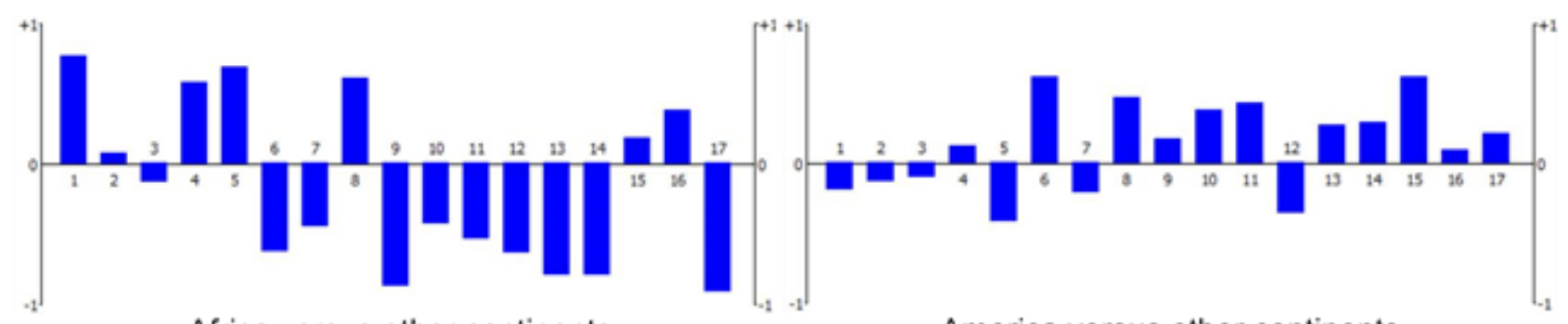

Africa versus other continents

America versus other continents

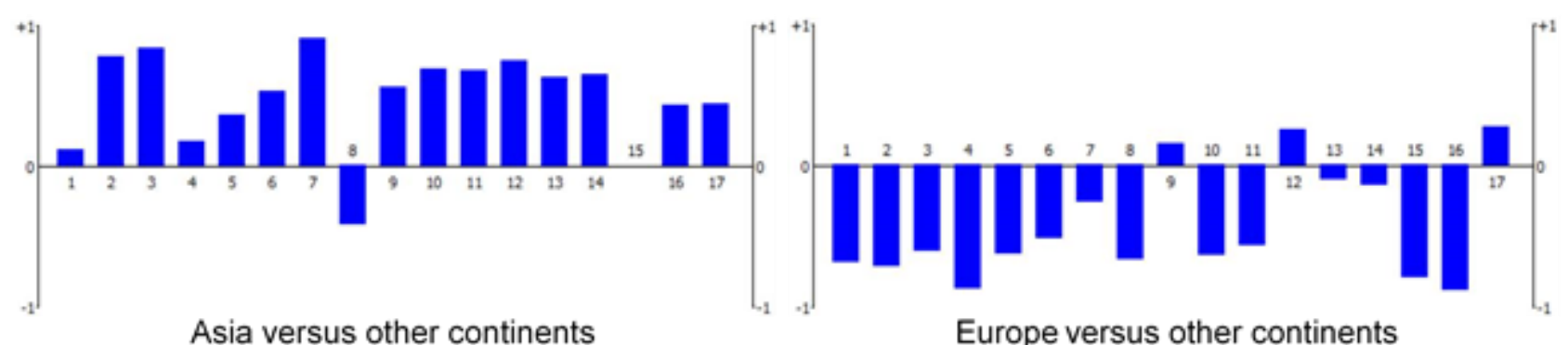

Figure 2 GAIA action profiles

Compared to all other continents:

- African metallurgical and mining industry prefers more often to follow: 1 No poverty, 5 Gender equality, 8 Decent work and economic growth, 4 Quality education, 16 Peace, justice and strong institutions, 15 Life on land, and 2 Zero hunger.

- American metallurgical and mining industry prefers most often to follow the majority of the SDGs: 6 Clean water and sanitation, 15 Life on land, 8 Decent work and economic growth, 11 Sustainable cities and communities, 10 Reduced inequalities, 14 Life below water, 13 Climate action, 17 Partnerships for the goals, 9 Industry, innovation and infrastructure, 4 Quality education, and 16 Peace, justice and strong institutions.

- $\quad$ Asian metallurgical and mining industry prefers more often to follow all the SDSs except: 8 Decent work and economic growth and 15 Life on land.

- European metallurgical and mining industry prefers more often to follow: 17 Partnerships for the goals, 12 Responsible consumption and production, and 9 Industry, innovation and infrastructure.

\section{CONCLUSIONS}

Worldwide SDGs preferences reflect the character of the metallurgical and mining industry. It is a very capitalintensive industry (8 Decent work and economic growth), it requires large row materials and energy resources (12 Responsible consumption and production), it belongs to the larger employers, but with a high risk of injury ( 3 Good health and well-being), it needs huge technological and ecological investments for its prosperity ( 9 Industry, innovation and infrastructure), and it is one of the biggest polluters (13 Climate action).

However, the study shows that there are relatively high differences in preferences across the continents. In our opinion, it reflects the basic economic continent conditions. This is most evident in the case of African metallurgical and mining industry. Compared to the rest of the world the industry prefers more often existential SDGs related to poverty, hunger, peace, education and economic growth. On the contrary, the economically more developed rest of the world prefers more often SGDs like 17 Partnerships for the goals, 9 Industry, innovation and infrastructure, 13 Climate action, 14 Life below water (see GAIA action profile "Africa versus other continents" in Figure 2). 


\section{ACKNOWLEDGEMENTS}

The work was supported by the specific university research of Ministry of Education, Youth and Sports of the Czech Republic at VSB - Technical University of Ostrava, projects no. SP2020/60 and SP2020/61, and Operational Programme Education for Competitiveness Project no. CZ.1.07/2.3.00/20.0296

\section{REFERENCES}

[1] VAN MARREWIJK, M., WERRE, M. Multiple levels of corporate sustainability. Journal of Business Ethics, 2003, vol. 44, no. 2-3, pp. 107-119.

[2] Lo, S.-F. and SHEU, H.-J. Is corporate sustainability a value-increasing strategy for business? Corporate Governance: An International Review, 2007, vol. 15, no. 2, pp. 345-358.

[3] World Commission on Environment and Development. Our Common Future. Oxford: Oxford University, 1987.

[4] ELKINGTON, J. Partnerships from cannibals with forks: The Triple Bottom Line of 21st-century business. Environmental Quality Management, 1998, vol. 8, no. 1, pp. 37-51.

[5] DAS, D. Development and validation of a scale for measuring sustainable supply chain management practices and performance. Journal of Cleaner Production, 2017, vol. 164, pp. 1344-1362.

[6] Governance \& Accountability Institute. FLASH REPORT: 86\% of S\&P 500 Index® Companies Publish Sustainability / Responsibility Reports in 2018 [online]. [viewed 2020-05-23]. Available from: https://www.gainstitute.com/press-releases/article/flash-report-86-of-sp-500-indexR-companies-publish-sustainabilityresponsibility-reports-in-20.html.

[7] United Nations. Sustainable Development Goals, Knowledge Platform [online]. [viewed 2020-05-23]. Available from: https://sustainabledevelopment.un.org/.

[8] BRANS, J.P., VINCKE, P. Note - a preference ranking organisation method: (the PROMETHEE method for multiple criteria decision-making). Management science. 1985, vol. 31, no. 6, pp. 647-656.

[9] SARRAZIN, R., DE SMET, Y., ROSENFELD, J. An extension of PROMETHEE to interval clustering. Omega. 2018, vol. 80, pp. 12-21.

[10] BRANS, J.P., DE SMET, Y. PROMETHEE methods. In: Greco S., Ehrgott M., Figueira J. (eds) Multiple riteria Decision Analysis. International Series in Operations Research \& Management Science, vol 233. Springer, New York, NY, 2016.

[11] United Nations Global Compact. Our Participants [online]. [viewed 2020-05-23]. Available from: https://www.unglobalcompact.org/what-is-gc/participants/.

[12] PODVEZKO, V., PODVIEZKO, A. Dependence of multi-criteria evaluation result on choice of preference functions and their parameters. Technological and Economic Development of Economy, 2010, vol. 16, no. 1, pp. 143-158. 